\title{
Theoretical study of the interactions involved in the inhibition of Mycobacterium tuberculosis methionine aminopeptidase by several molecules
}

\section{Boucherit Hanane*, Chikhi Abdelouahab, Bensegueni Abderrahmane, Merzoug Amina, Hioual khadidja Soulef, Mokrani El Hassen}

Laboratory of Applied Biology and Health, Department of Biochemistry-Microbiology, Faculty of Natural And Life Sciences, University of Constantine 1, Constantine, Algeria

\section{Email address:}

Boucherithanane@hotmail.fr (B. Hanane)

\section{To cite this article:}

Boucherit Hanane, Chikhi Abdelouahab, Bensegueni Abderrahmane, Merzoug Amina, Hioual khadidja Soulef, Mokrani El Hassen. Theoretical Study of the Interactions Involved in the Inhibition of Mycobacterium Tuberculosis Methionine Aminopeptidase by Several Molecules. Computational Biology and Bioinformatics. Vol. 2, No. 5, 2014, pp. 63-73. doi: 10.11648/j.cbb.20140205.11

\begin{abstract}
With the development of computer tools in the past 20 years, molecular modeling and more precisely molecular docking has quickly entered the area of biological research. Two programs of molecular docking, Surflex and GOLD (Genetic Optimization for Ligand Docking), have been developed to assist in the development of molecules with therapeutic activity. With the RMSD (Root Mean Square Deviation) values lower than $2 \AA$ and the coefficient of correlation close to 1, the performances of Surflex and GOLD software's are clearly proven and perfectly adapted to the different molecular structures used in this study. They have been used to study the inhibition of 3IU7, a methionine aminopeptidase belonging to Mycobacterium tuberculosis, by various molecules of ligands from the literature aimed to find new anti-tuberculosis drugs. The evaluation of the affinity and the energy of interaction of these molecules made it possible to release those presenting the best inhibiting effect, in accordance with $\mathrm{IC}_{50}$ values obtained from the literature. It is the compound $\mathrm{TO}$, which the values of Fitness and Affinity are respectively 57.35 and $3.10 \mathrm{M}^{-1}$. The interactions types responsible for the stability of the various complexes are Van der Waals and hydrogen bonds.
\end{abstract}

Keywords: Protein-Ligand Interactions, Molecular Docking, Surflex, GOLD, RMSD, the Coefficient of Correlation, Methionine Aminopeptidase

\section{Introduction}

The interaction between a protein and its substrate is the first step in most biological reactions. Understand its mode of operation and define which residues are involved, is therefore essential to be able to explain the mechanisms that influence the affinity between two molecules. Similarly, the discovery of new drugs activating or inhibiting the biological activity of a protein can only be done by predicting their respective affinity. It is for this purpose that molecular modeling techniques, grouped under the name of molecular docking have been developed.

The molecular docking in silico aims to predict the structure of a molecular complex from the isolated molecules, which is considerably easier to implement, less expensive and faster than the use of experimental methods (in vitro).
Docking software's are therefore very useful tools in biology, pharmacy and medicine, because most of the active site are small molecules (ligand) that interact with a biological target of therapeutic interest, usually protein (receptor), in order to influence the mechanism in which this protein is involved [1].

Docking is one of the commonly used computational methods in structure based drug design. Docking is the process of fitting of the ligand into the receptor. It not only gives an idea about how the ligand is going to bind with the receptors but also about up to what extent conformational changes can be brought in the receptor structure . Docking comprises two distinct tasks, the first being the prediction of favorable binding geometries for a small molecule in the binding site of a target (protein) and secondly, the estimation of the binding free energy of the complex formed, also referred to as scoring. 
In recent years, tuberculosis is experiencing a worrying resurgence in both industrialized and in developing countries. The resurgence of the disease is due in part to the synergy pronounced between the human immunodeficiency virus (HIV) and tuberculosis and also the emergence of resistant strains of Mycobacterium specific antibiotics [2]. This necessitates the development of new therapeutic strategies, based particularly on the search for new molecules that act as TB.

In this context, methionine aminopeptidase (MetAP) is used as a promising target for developing new antibiotics because it is essential for bacterial survival. The MetAP is a metalloprotease that removes the $\mathrm{N}$-terminal methionine during protein synthesis, one of the critical steps in the maturation of proteins [3].

The purpose of this study is:

- Test, at first, the reliability of Surflex and GOLD programs used in this study to examine the protein-ligand interactions

- Secondly, to study the inhibition of methionine aminopeptidase by the methods of molecular docking. We are interested to determine the mode of interaction during the binding of the inhibitor to the enzyme during formation of the complex MetAP-inhibitor with better complementarity determining the affinity of the complex formed. The compound that has the greatest affinity is the one that present the best activity and subsequently a better inhibition. These results will probably help in the development of an effective therapeutic tool in the fight against the development of tuberculosis.

\section{Materials and Methods}

\subsection{Evaluation of Docking Programs}

\subsubsection{The RMSD (Root Mean Square Deviation)}

Equal to the average of the deviation of each of atoms compared to the original molecule. The best value of mean RMSD between the placing of the ligand calculated by the software and the conformation in the experimental complex is the smallest possible. The ratio accepted is 2 angstroms beyond which the prediction is considered irrelevant. The current standard for evaluating the performance of a docking program is to make a test from hundreds of protein-ligand complexes crystallized $[4,5]$.

Two molecular docking programs were tested Surflex (v $1.3,2005)$ and $\operatorname{GOLD}(5.0 .1,2011)$. This test was performed on 144 complexes available in the PDB and the RMSD determined. The prediction RMSD is acceptable if the value does not exceed $2 \AA$.

\subsubsection{The Correlation Coefficient (R)}

The correlation coefficient indicates the degree of linear relationship between two data sets, and takes values between -1 and 1 . If there is no linear relationship between the two sets of data, the coefficient correlation is very close to zero, and we say that the two variables are not correlated [6].

To study the correlation between the score obtained by the molecular docking and the biological activity $\left(\mathrm{IC}_{50}\right)$, we used different inhibitors of methionine aminopeptidase (MetAP), these inhibitors known through the articles. A total of 100 molecules of three different bacteria: Mycobacterium tuberculosis [2], Escherichia coli [7, 8, and 9] and Staphylococcus aureus [8] were tested. Availability of their $\mathrm{IC}_{50}$ values is among the criteria for selection of these molecules used to test the reliability of Surflex and GOLD programs using the correlation coefficient.

\subsection{Preparation Molecules}

\subsubsection{The Structures of the Enzyme (MetAP)}

The structures of the enzyme (MetAP) come from the PDB (Protein Data Bank), the largest archive of structural data of biological macromolecules such as proteins and nucleic acids. This information is principally obtained by Xray crystallography and nuclear magnetic resonance (NMR). Much information associated with each structure is accessible to the entire scientific community, through a web server (http://www.rcsb.org/pdb/). One can find the corresponding sequence, its atomic coordinates, the experimental conditions and 3D images [10].

\subsubsection{Selection of Crystallographic Structure}

We chose three codes with good quality of enzyme (MetAP); 3IU7 (MetAP Mycobacterium tuberculosis) 2GG2 (MetAP from Escherichia coli) and 1QXY (MetAP Staphylococcus aureus). The characteristics of these enzymes are summarized in Table 1 below.

Table 1. Main characteristics of the codes 3IU7, 2GG2 and 1QXY [11]

\begin{tabular}{lllllll}
\hline Code & Resolution $\left(\mathbf{A}^{\circ}\right)$ & the R factor & Classification & Number of chain & Number of AA by chain & Number of atoms per chain \\
\hline 3IU7 & 1.40 & 0.172 & 3.4 .11 .18 & 1 & 285 & 2167 \\
2GG2 & 1.00 & 0.136 & 3.4 .11 .18 & 1 & 264 & 2176 \\
1QXY & 1.04 & 0.144 & 3.4 .11 .18 & 1 & 251 & 1910 \\
\hline
\end{tabular}

\subsubsection{Preparation of Molecules for the Docking}

The protein-ligand complex is downloaded from the PDB by inserting its code ID in the . $p d b$ format. GOLD directly uses the.$p d b$ format and does not require advance preparation. In contrast, Surflex requires .mol2 format. So the two molecules of the complex (enzyme-ligand) are separated using software Viewerlite. The water molecules and other compounds are removed from the crystallization structure. The hydrogen is added to the structure, respecting the state of protonation of residues. They are then transformed into the .mol2 format with a program available for free Open Babel. 


\subsubsection{Design of Inhibitors-MetAP}

The ArgusLab program $(4.0 .1,2003)$ [12] is a free software used to build the various inhibitors MetAP. It has a bank of atoms in different states of hybridization to construct all possible chemical groups. The geometry of the ligand is optimized using the semi empirical method PM3 (Parametric Method3) and stored in the .mol format and then transformed into the .mol2 format using Open Babel program.

\subsubsection{Programs Used}

\section{- Surflex}

Surflex $(1.3,2005)$ is an algorithm for rapid docking able to dock ligands in an environment consisting of amino acids with good precision. In this study, the standard parameters of Surflex were used by default.

The docking is performed in three steps [13]:

- Choosing how to identify the active site, either from the ligand or receptor;

- Build a pseudo-molecule (Protomol) will be targeted the different ligands;

- Docking one or more ligands.

- GOLD (Genetic Optimization for Ligand Docking)

GOLD is a program for calculating the docking modes of small molecules in the active sites of proteins and is provided as part of GOLD Suite, a suite of programs for viewing and manipulating structures (Hermes $\mathrm{v}$ 1.4), for the proteinligand docking (GOLD $\vee$ 5.0.1) and for processing and visualization the results of docking (GoldMine v 1.3).

Its main advantages are its reliability to predict crystal structures for complex protein-ligand and the use of an effective genetic algorithm.

\subsection{Inhibition of $3 I U 7$ by GOLD}

\subsubsection{Choice of $3 I U 7$}

Ten three-dimensional structures for methionine aminopeptidase Mycobacterium tuberculosis are available on the PDB, identified by codes: 3IU7, 3IU8, and 3IU9, 1YJ3, 1YIN, 3PKA, 3PKB, 3PKC, 3PKD and 3PKE. The code 3IU7 was chosen for this study because it is compromise between good resolution and the presence of a co-crystallized inhibitor.

\subsubsection{Lipinski Rule}

Lipinski's Rule of Five is a rule of thumb to determine if a chemical compound with a certain pharmacological or biological activity has properties that would make it a likely orally active drug in humans.

The rule made by Christopher Lipinski [14]. Each drug must comply with several basic criteria, such as low cost of production, be soluble, stable, but must also conform to the schedules associated with its pharmacological properties of absorption, distribution, metabolism, excretion and toxicity (ADME/Tox).

Lipinski's Rule of Five states that an orally active drug must complete three of these fives proprieties:

- No more than 5 hydrogen bond donors

- No more than 10 hydrogen bond acceptors
- No more than 15 rotatable bonds

- The Molecular weight is over $500 \mathrm{~g} / \mathrm{mol}^{-1}$

- The $\log \mathrm{P}$ is over 5

\subsection{Inhibition of $3 I U 7$ by Various Inhibitors}

We have selected four compounds that act on MetAP Mycobacterium tuberculosis. The structures of the ligands are represented in the table 2 below.

Table 2. Structure of ligands studied

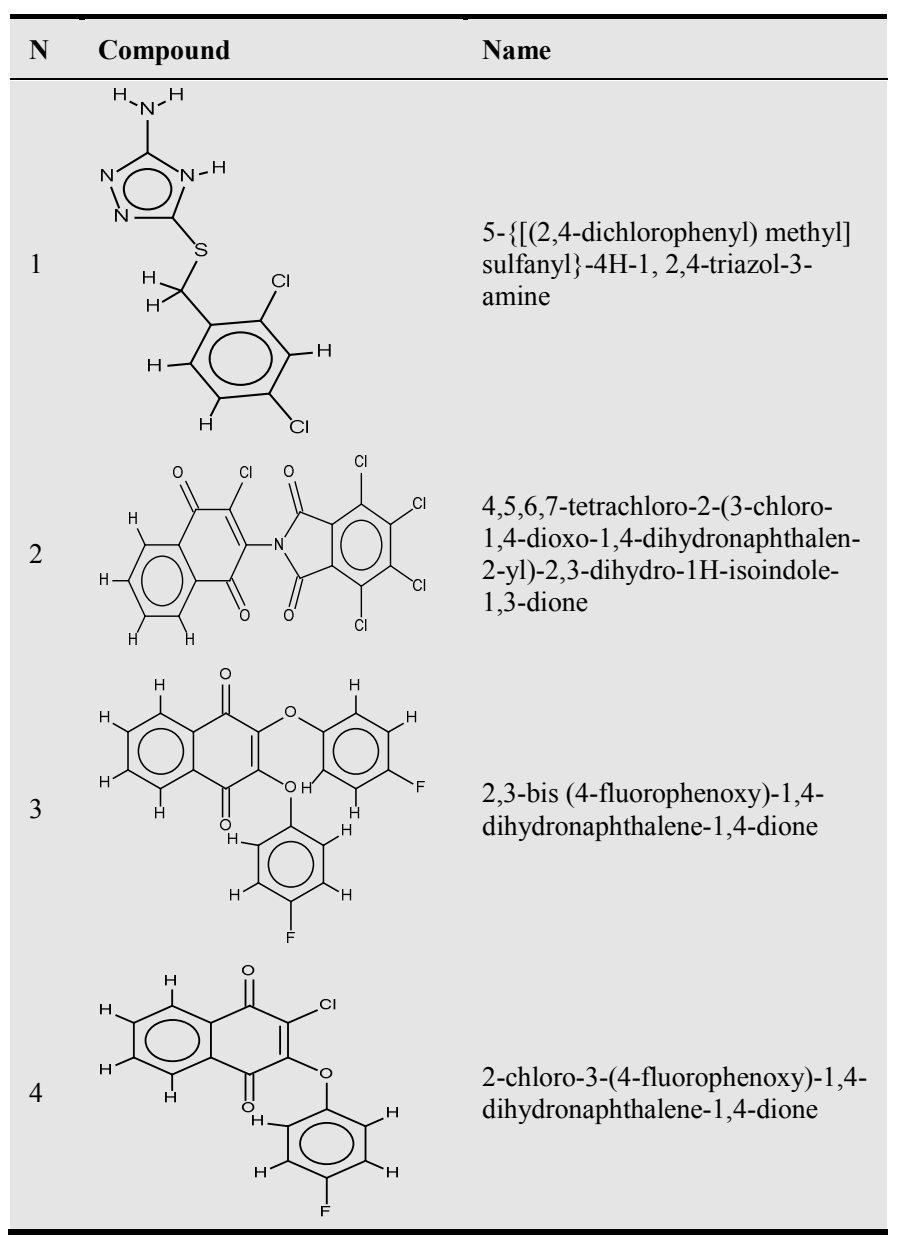

\section{Results and Discussion}

\subsection{Reliability of Programs Used}

\subsubsection{The RMSD}

The performance of both software's was evaluated on 144 protein-ligand complex from PDB. The root mean square deviations between the position of the crystallographic complex and those ligands docked by Surflex and GOLD were calculated. A correct prediction (positive result) is defined by the RMSD less than $2 \AA$. In the following graphs, the results are given in percent (\%) at various intervals of RMSD represented by different colors, for both programs: Surflex and GOLD. 


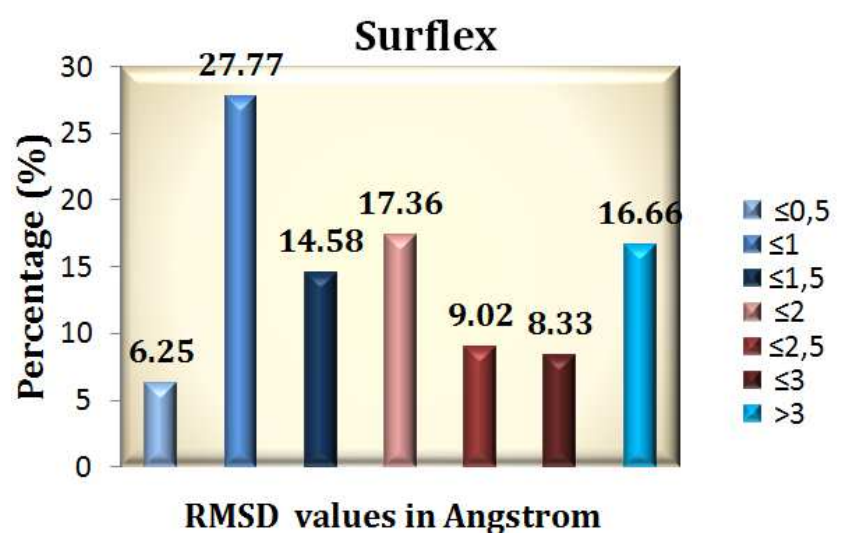

Graph 1. Results in\% obtained by Surflex at various intervals of RMSD $(\AA)$

\section{GOLD}

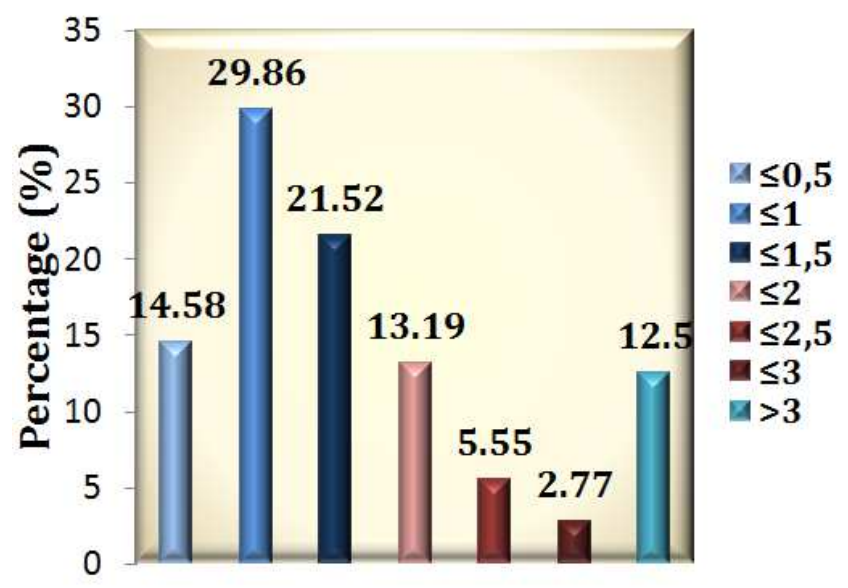

\section{RMSD values in Angstrom}

Graph 2. Results in\% obtained by GOLD at various intervals of RMSD ( $\AA$ )

The minimum RMSD overall is $0.27 \AA$, while the maximum is $7.67 \AA$. The majority of positive results is in the range 0.5 to $1 \AA$ for Surflex and $0.5-1.5 \AA$ for GOLD.

We note from these results that GOLD program reproduces well the experimental data, and to a lesser extent Surflex. Indeed, $79.16 \%$ of RMSD values are less than or equal $2 \AA$ for the former and $66 \%$ for the second. However, the computing time required by GOLD program for docking of a ligand is longer than the time required by the program Surflex. This parameter is not negligible if the software is used to screen large numbers of molecules. It is clear from this graph that the RMSD values are consistent with the results of Chikhi A and Bensegueni A [1] and Gabb et al. [14 15], showing that any program the docking is successful when the RMSD is less than $2 \AA$. This is also consistent with the results obtained by Zaheer-ul-Haq et al. [15 16], where six docking programs were used: FRED, GOLD, MOE, AutoDock, FlexX and Surflex-Dock, for a comparative study to determine their ability to reproduce poses via the experimental RMSD. FRED was the best followed by Surflex-Dock and GOLD. In the same year [16 17] evaluated the performance of four programs: GOLD, AutoDock, Surflex-Dock and FRED by calculating the RMSD, the best results were obtained by GOLD and FRED. Thus, this software can be used to predict the interactions MetAPinhibitors.

\section{Reliability program}

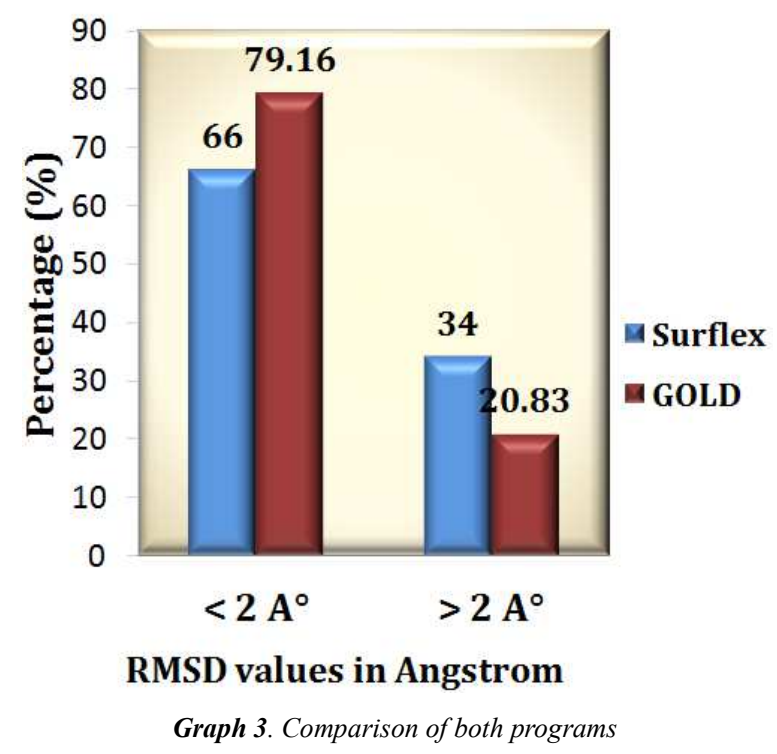

\subsubsection{The Correlation Coefficient}

The linear regression analysis was performed on several complexes (MetAP-inhibitors), the biological activity has been tested. The linear regression analysis yielded a correlation coefficient for each of the programs used (Table 3).

Table 3. Values of the correlation coefficient

\begin{tabular}{lll}
\hline programs & Surflex-dock & GOLD \\
\hline The correlation coefficient & 0.76 & 0.64 \\
\hline
\end{tabular}

Inhibitors of MetAP from the literature were investigated. A total of 100 structures (MetAP-inhibitors) were tested by both programs Surflex and GOLD. In both cases, the value of the correlation coefficient is greater than $0.5(|\mathrm{r}| \geq 0.5)$ [18]. So there is significant correlation between the two parameters analyzed, namely the biological activity represented here by $-\log \mathrm{IC}_{50}$ and results given by the two docking program Surflex (Affinity) and GOLD (Fitness).

Surflex establishes a good correlation $(\mathrm{r}=0.76)$ which is in agreement with the results of Chikhi $A$ and Bensegueni A. (2010) [19] and Kamel M. M. et al. (2010) [20]. However, the correlation obtained by GOLD in conjunction with the score function GoldScore (Fitness) is slightly lower, but still at an acceptable level $(\mathrm{r}=0.64)$, as clearly shown in figures 1 and 2. This result is comparable to that reported by Maouche A. $T$ et al. (2008) [21] using the GOLD software in connection with another score function (Chemscore).

Note interesting interactions between different inhibitors and MetAP with affinity and fitness values sufficiently high, in particular for the four complexes 17, 19, 21 and 91 with $5.40 \mathrm{M}^{-1}$ (Affinity) - 64.83 (Fitness), $4.17 \mathrm{M}^{-1}$ - 63.46, 4.87 $\mathrm{M}^{-1}-60.69$ and $4.17 \mathrm{M}^{-1}-64.31$ respectively. 
Table 4. Results of linear regression analysis of inhibitors-MetAP

\begin{tabular}{|c|c|c|c|c|}
\hline $\mathbf{N}$ & $\mathrm{IC}_{50}(\mu \mathrm{M})$ & $-\log I C_{50}$ & Affinity $\left(M^{-1}\right)$ & Fitness \\
\hline 1 & $10 \pm 3.5$ & -1 & 3.23 & 55,42 \\
\hline 2 & $5.2 \pm 1$ & -0.71 & 4.26 & 57,52 \\
\hline 3 & $4.6 \pm 0.4$ & -0.66 & 4.75 & 54,97 \\
\hline 4 & $3.9 \pm 0.5$ & -0.59 & 2.49 & 57,25 \\
\hline 5 & $3.4 \pm 0.2$ & -0.53 & 4.36 & 61,52 \\
\hline 6 & $2.6 \pm 0.4$ & -0.41 & 4.26 & 55,68 \\
\hline 7 & $2.4 \pm 0.3$ & -0.38 & 4.56 & 56,19 \\
\hline 8 & $2.1 \pm 0.3$ & -0.32 & 4.34 & 54,64 \\
\hline 9 & $1.7 \pm 0.2$ & -0.23 & 4.34 & 54,38 \\
\hline 10 & $1.7 \pm 0.1$ & -0.23 & 4.38 & 55,51 \\
\hline 11 & $1.2 \pm 0.1$ & -0.079 & 4.04 & 62,1 \\
\hline 12 & $0.99 \pm 0.13$ & 0.004 & 5.72 & 62,52 \\
\hline 13 & $0.97 \pm 0.02$ & 0.013 & 5.61 & 62,59 \\
\hline 14 & $0.78 \pm 0.03$ & 0.1 & 5.02 & 60,78 \\
\hline 15 & $0.55 \pm 0.08$ & 0.259 & 4.29 & 53,89 \\
\hline 16 & $0.54 \pm 0.03$ & 0.26 & 4.66 & 57,99 \\
\hline 17 & $0.46 \pm 0.01$ & 0.33 & 5.40 & 64,83 \\
\hline 18 & $0.38 \pm 0.02$ & -0.42 & 3.81 & 55,67 \\
\hline 19 & $0.16 \pm 0.02$ & 0.79 & 4.17 & 63,46 \\
\hline 20 & 1.75 & -0.24 & 4.09 & 75,76 \\
\hline 21 & 0.25 & 0.6 & 4.87 & 60,69 \\
\hline 22 & 0.25 & 0.6 & 5.33 & 59,53 \\
\hline 23 & 0.55 & 0.259 & 4.17 & 63,11 \\
\hline 24 & 0.55 & 0.25 & 4.72 & 66,34 \\
\hline 25 & 1.25 & -0.096 & 4.00 & 60,21 \\
\hline 26 & 1.50 & -0.176 & 3.47 & 60,94 \\
\hline 27 & $0.1 \pm 0.01$ & 1 & 4.86 & 62,64 \\
\hline 28 & 5 & -0.69 & 3.63 & 50,62 \\
\hline 29 & 1.69 & -0.22 & 5.38 & 71,26 \\
\hline 30 & 0.044 & 1.35 & 4.71 & 64,41 \\
\hline 31 & 19 & -1.27 & 2.10 & 53,13 \\
\hline 32 & 16 & -1.2 & 2.92 & 54,73 \\
\hline 33 & $18.3 \pm 1.3$ & -1.26 & 2.24 & 47,86 \\
\hline 34 & $41.7 \pm 2.3$ & -1.62 & 2.09 & 48,54 \\
\hline 35 & $38.9 \pm 3.7$ & -1.58 & 2.97 & 39,18 \\
\hline 36 & $17.9 \pm 1.9$ & -1.25 & 2.81 & 41,45 \\
\hline 37 & $19.4 \pm 3.9$ & -1.28 & 3.40 & 42,22 \\
\hline 38 & $45.5 \pm 3.4$ & -1.65 & 3.33 & 45,78 \\
\hline 39 & $40.1 \pm 1.5$ & -1.6 & 3.04 & 42,6 \\
\hline 40 & $29.2 \pm 1.3$ & -1.46 & 3.20 & 49,26 \\
\hline 41 & $4.9 \pm 0.1$ & -0.69 & 2.66 & 47,02 \\
\hline 42 & $19.9 \pm 2.2$ & -1.29 & 3.06 & 42,4 \\
\hline 43 & $22.8 \pm 1.9$ & -1.357 & 3.03 & 41,12 \\
\hline 44 & $22.4 \pm 2.4$ & -1.35 & 3.60 & 50,94 \\
\hline 45 & $22.0 \pm 2.7$ & -1.34 & 3.05 & 44,51 \\
\hline 46 & $18.8 \pm 0.7$ & -1.27 & 3.07 & 42,54 \\
\hline 47 & $21.2 \pm 1.3$ & -1.32 & 3.08 & 49,68 \\
\hline 48 & $7.2 \pm 1.8$ & -0.85 & 3.67 & 54,05 \\
\hline 49 & $>100$ & -2 & 3.30 & 42,53 \\
\hline 50 & $>100$ & -2 & 2.50 & 49,76 \\
\hline 51 & $>100$ & -2 & 3.34 & 48,89 \\
\hline 52 & $>100$ & -2 & 1.23 & 52,75 \\
\hline 53 & $>100$ & -2 & 2.08 & 51,71 \\
\hline 54 & $>50$ & -1.69 & 1.72 & 56,28 \\
\hline 55 & $>50$ & -1.69 & 3.07 & 49,82 \\
\hline 56 & $>50$ & -1.69 & 3.53 & 52,14 \\
\hline 57 & $21.3 \pm 10.6$ & -1.32 & 3.90 & 52,37 \\
\hline 58 & $1.79 \pm 0.49$ & -0.25 & 3.68 & 57,53 \\
\hline
\end{tabular}

\begin{tabular}{lllll}
\hline $\mathbf{N}$ & $\mathbf{I C}_{\mathbf{5 0}}(\boldsymbol{\mu} \mathbf{M})$ & $-\mathbf{L o g} \mathbf{I C}_{\mathbf{5 0}}$ & Affinity $\left(\mathbf{M}^{-\mathbf{1}}\right)$ & Fitness \\
\hline 59 & $3.74 \pm 0.52$ & -0.57 & 3.50 & 57,67 \\
60 & $>30$ & -1.47 & 3.09 & 41,09 \\
61 & $>50$ & -1.69 & 3.04 & 45,2 \\
62 & $>50$ & -1.69 & 2.76 & 40,14 \\
63 & $>30$ & -1.47 & 3.83 & 51,18 \\
64 & $>50$ & -1.69 & 2.23 & 53,25 \\
65 & $>50$ & -1.69 & 3.09 & 68,07 \\
66 & $>50$ & -1.69 & 2.62 & 41,5 \\
67 & 200 & -2.3 & 3.45 & 52,65 \\
68 & 4.61 & -0.66 & 4.55 & 59,61 \\
69 & $4.3 \pm 0.6$ & -0.63 & 4.09 & 54,89 \\
70 & $2.4 \pm 0.5$ & -0.38 & 5.72 & 73,86 \\
71 & $1.5 \pm 0.2$ & -0.17 & 4.88 & 50,09 \\
72 & $1.3 \pm 0.3$ & -0.11 & 5.00 & 49,78 \\
73 & $0.57 \pm 0.08$ & 0.24 & 4.60 & 51,68 \\
74 & 0.11 & 0.95 & 4.55 & 56,75 \\
75 & $0.47 \pm 0.06$ & 0.32 & 4.11 & 52,94 \\
76 & 0.58 & 0.23 & 6.65 & 51,56 \\
77 & 2.00 & -0.3 & 5.47 & 77,43 \\
78 & $0.21 \pm 0.02$ & 0.67 & 4.30 & 48,77 \\
79 & $4.4 \pm 1.7$ & -0.64 & 4.49 & 43,07 \\
80 & $22.9 \pm 1.9$ & -1.359 & 2.97 & 72,57 \\
81 & $16.0 \pm 1.9$ & -1.2 & 3.00 & 71,93 \\
82 & $8.7 \pm 0.2$ & -0.93 & 3.30 & 63,34 \\
83 & $>100$ & -2 & 2.14 & 57,46 \\
84 & $>50$ & -1.69 & 2.91 & 60,59 \\
85 & $9 \pm 1.3$ & -0.95 & 6.29 & 57,25 \\
86 & $7.2 \pm 0.1$ & -0.85 & 4.35 & 51,24 \\
87 & $0.24 \pm 0.04$ & 0.619 & 3.92 & 57,51 \\
88 & 2.8 & -0.44 & 1.00 & 60,01 \\
89 & 1.7 & -0.23 & 7.03 & 71,05 \\
90 & 0.137 & 0.86 & 3.14 & 62,87 \\
91 & 0.154 & 0.81 & 4.17 & 64,31 \\
92 & $35.9 \pm 0.6$ & -1.55 & 4.48 & 41,96 \\
93 & $6.6 \pm 1.2$ & -0.81 & 1.76 & 43,89 \\
94 & $22.5 \pm 1.5$ & -1.35 & 4.54 & 55,02 \\
95 & $16.4 \pm 6.8$ & -1.21 & 4.65 & 52,32 \\
96 & 138 & -2.13 & 5.06 & 53,15 \\
97 & 71.4 & -1.85 & 4.43 & 53,71 \\
98 & 57.5 & -1.75 & 4.17 & 55,18 \\
99 & 84.2 & -1.92 & 4.57 & 53,9 \\
100 & 57.3 & -1.75 & 3.92 & 54,39 \\
\hline & & & &
\end{tabular}

Affinity

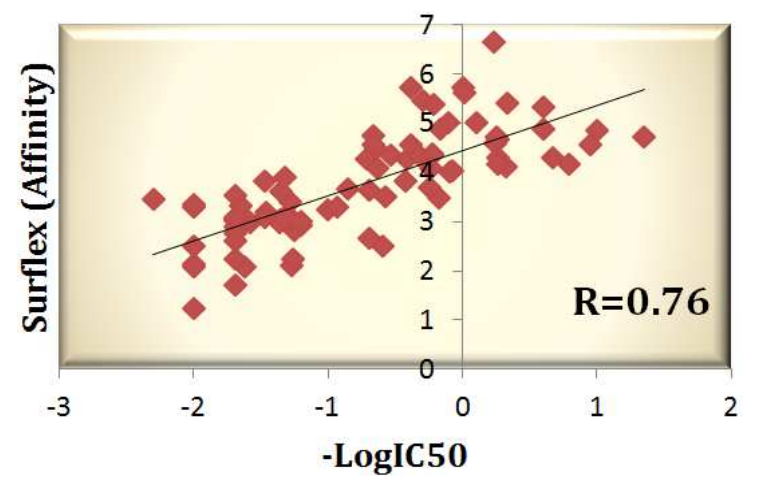

Figure 1. correlation between biological activity (-Log $\left.I_{50}\right)$ of MetAP inhibitors and Affinities given by Surflex 


\section{Fitness}

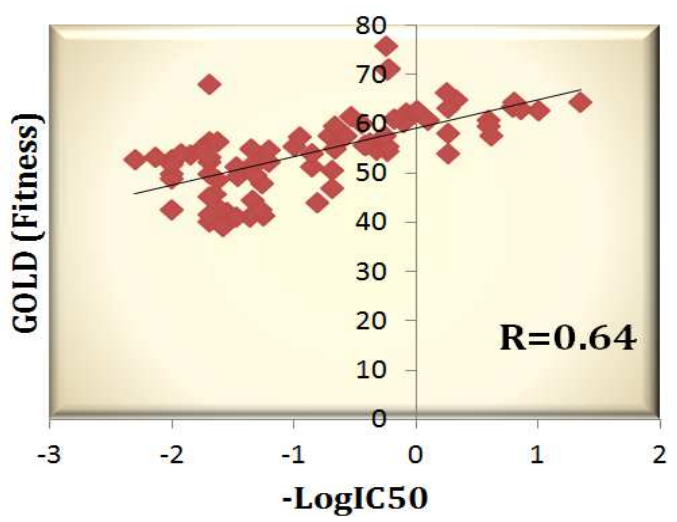

Figure 2. Correlation between biological activity (-Log $\left.I C_{50}\right)$ of MetAP inhibitors and Fitness given by GOLD

\subsection{Study of the Interactions Involved in the Inhibition of $3 I U 7$ by Various Molecules}

\subsubsection{Docking Inhibitors of MetAP}

Table 5. Results of docking with Surflex and GOLD

\begin{tabular}{|c|c|c|c|c|}
\hline $\mathbf{N}$ & Compounds & IC50 $(\mu \mathrm{M})$ & Affinity $\left(M^{-1}\right)$ & Fitness \\
\hline 1 & 1 (FCD) & 16 & 2.78 & 56.72 \\
\hline 2 & 2 & 14 & 3.26 & 50.45 \\
\hline 3 & 3 & 14 & 3.09 & 54.85 \\
\hline 4 & 4 & 37 & 2.39 & 56.66 \\
\hline 5 & 5 & 18 & -1.50 & 55.78 \\
\hline 6 & 6 & 26 & 6.28 & 59.50 \\
\hline 7 & 7 (TO3) & 0.58 & 2.08 & 56.15 \\
\hline 8 & 8 (TO7) & 0.24 & 3.10 & 57.35 \\
\hline 9 & 2 & 8.7 & 3.30 & 57.53 \\
\hline 10 & 3 & 7.2 & 3.67 & 54.05 \\
\hline 11 & 4 & 6.6 & 1.76 & 43,89 \\
\hline 12 & 5 & $>100$ & 3.30 & 42.53 \\
\hline 13 & 6 & $>100$ & 2.50 & 49.76 \\
\hline 14 & 7 & $>100$ & 3.34 & 48.89 \\
\hline 15 & 8 & $>100$ & 2.14 & 57,46 \\
\hline 16 & 9 & $>100$ & 1.23 & 52.75 \\
\hline 17 & 10 & $>100$ & 2.08 & 51.71 \\
\hline 18 & 12 & $>50$ & 1.72 & 56.28 \\
\hline 19 & 13 & $>50$ & 2.91 & 60.59 \\
\hline 20 & 14 & $>50$ & 3.07 & 49.82 \\
\hline 21 & 15 & $>50$ & 3.53 & 52.14 \\
\hline 22 & 16 & $>50$ & 3.03 & 58.98 \\
\hline 23 & 17 & 21.3 & 3.90 & 52,37 \\
\hline 24 & 18 & 22.5 & 4.54 & 55.02 \\
\hline
\end{tabular}

\begin{tabular}{lllll}
\hline $\mathbf{N}$ & Compounds & IC50 $(\boldsymbol{\mu M})$ & Affinity $\left(\mathbf{M}^{-1}\right)$ & Fitness \\
\hline 25 & 19 & 16.4 & 4.65 & 52,32 \\
26 & 20 & 0.71 & 1.55 & 46,68 \\
27 & 21 & 1.79 & 3.68 & 57.06 \\
28 & 22 & 3.74 & 3.50 & 57.67 \\
29 & 23 & $>30$ & 3.09 & 41.09 \\
30 & 24 & $>50$ & 3.04 & 45.20 \\
31 & 25 & $>50$ & 2.76 & 40.14 \\
32 & 26 & $>30$ & 3.83 & 51.18 \\
33 & 27 & $>50$ & 2.23 & 53.25 \\
34 & 28 & $>50$ & 3.09 & 68.07 \\
35 & 29 & $>50$ & 2.62 & 41.50 \\
\hline
\end{tabular}

The docking of 35 molecules taken from the literature is made on the structure of the protein co-crystallized with the FCD (crystallographic structure 3IU7). We considered interesting to test these inhibitors, compare their scores (Affinity, Fitness) from the original ligand and suggest the best inhibitor of the enzyme MetAP. The docking results are shown in table 5 .

The first result (Affinity, Fitness) is that of the reference ligand and the others correspond to different inhibitors from the literature. We chose this inhibitor as a reference because it is the first ligand proposed as an inhibitor of MetAP Mycobacterium tuberculosis.

Among the complexes listed in Table 5, we selected only the best results. Those who have a significant inhibitory activity on MetAP ( $\mathrm{IC}_{50}$ lower than the initial ligand), with a highest score of docking).

Table 6. Results obtained by Surflex

\begin{tabular}{lllll}
\hline $\mathbf{N}$ & Compounds & Log-0 & Crash & Polar \\
\hline 8 & TO7 & 3.10 & 1.59 & 2.34 \\
9 & 2 & 3.30 & 1.26 & 0.85 \\
27 & 21 & 3.68 & 3.76 & 0.00 \\
28 & 22 & 3.50 & 0.46 & 0.00 \\
\hline
\end{tabular}

- Log-0 is the best solution among the ten that are given by default by the software. Log-0 represents the affinity.

- The second or crash value corresponds to the degree of penetration of inappropriate ligand in the protein.

- The last value, polar, is the level of contribution of polar interactions.

Table 7. Results obtained by GOLD

\begin{tabular}{lllllll}
\hline $\mathbf{N}$ & Compounds & Fitness & S (hb_ext) & S (vdw_ext) & S (hb_int) & S (int) \\
\hline 8 & TO7 & 57.35 & 21.41 & 30.04 & 0.00 & -5.36 \\
9 & 2 & 57.53 & 13.70 & 32.01 & 0.00 & -0.18 \\
27 & 21 & 57.07 & 11.30 & 34.61 & 0.00 & -1.82 \\
28 & 22 & 57.67 & 12.68 & 34.67 & 0.00 & -2.69 \\
\hline
\end{tabular}




\subsubsection{Lipinski Rule}

Before beginning the study of interactions between the enzyme and the 4 MetAP compounds, it is necessary to evaluate the parameters for validation as antibiotics (Table 8).
These indices were calculated under the code "Molinspiration" [22]. It allows you to draw molecules and calculate the important molecular properties directly on a web page.

Table 8. Lipinski rule for different inhibitors

\begin{tabular}{lllllll}
\hline $\mathbf{N}$ & Compounds & MW & nOH,NH & nO,N & ClogP & nrotb \\
\hline 8 & TO7 & 275.164 & 3 & 4 & 2.992 & 3 \\
9 & 2 & 475.498 & 0 & 5 & 5.331 & 1 \\
27 & 21 & 378.33 & 0 & 4 & 5.359 & 4 \\
28 & 22 & 302.688 & 0 & 3 & 4.119 & 2 \\
\hline
\end{tabular}

MW: molecular weight;

nOH, NH: number of H-bond donors;

$\mathrm{nO}, \mathrm{N}$ : number of $\mathrm{H}-$ bond acceptors;

Clog: $\log \mathrm{P}$;

nrotb: rotable bonds.

We find that almost all inhibitors studied respond to Lipinski rule of five; with absence of H-bond donors for molecules 2, 21 and 22. The compounds 2 and 21 have a log$\mathrm{P}$ greater than 5 .

The energetic and structural results for the docking of the structures studied (TO7, 2, 21 and 22) in the active site of MetAP have yielded the desired information on the specific mode of interaction of these inhibitors.

\subsubsection{Interaction of 4 ligands Selected}

- Interaction : 3IU7-TO7

The molecule TO7 has the highest score with the enzyme MetAP (Affinity $=3.10 \mathrm{M}^{-1}$ Fitness $=57.35$ ). There is a highly significant correlation between the interaction energy and its inhibitory effect $\left(\mathrm{IC}_{50}=0.24 \mu \mathrm{M}\right)$.

Visual analysis shows that the inhibitor TO7 is stabilized by the formation of two hydrogen bonds (shown in green) with His212 and Asp131 residues. The figure 3 shows that the N4 nitrogen ligand establishes a hydrogen bridge with the hydroxyl of the Asp131 residue, via its oxygen atom $\left(\mathrm{N}_{4} \ldots \ldots \mathrm{H}_{\mathrm{D} 2}-\mathrm{O}_{\mathrm{D} 2}-\mathrm{Asp} 131 ; \mathrm{d}=2.925 \AA\right)$. The $\mathrm{NH} 2$ group of the ligand makes a hydrogen bond with one of the nitrogen atoms of the residue His212 $\left(\mathrm{N}_{3}-\mathrm{H} \ldots \ldots . \mathrm{N}_{\mathrm{E} 2}-\mathrm{His} 212 ; \mathrm{d}=\right.$ $2.946 \AA$ ).

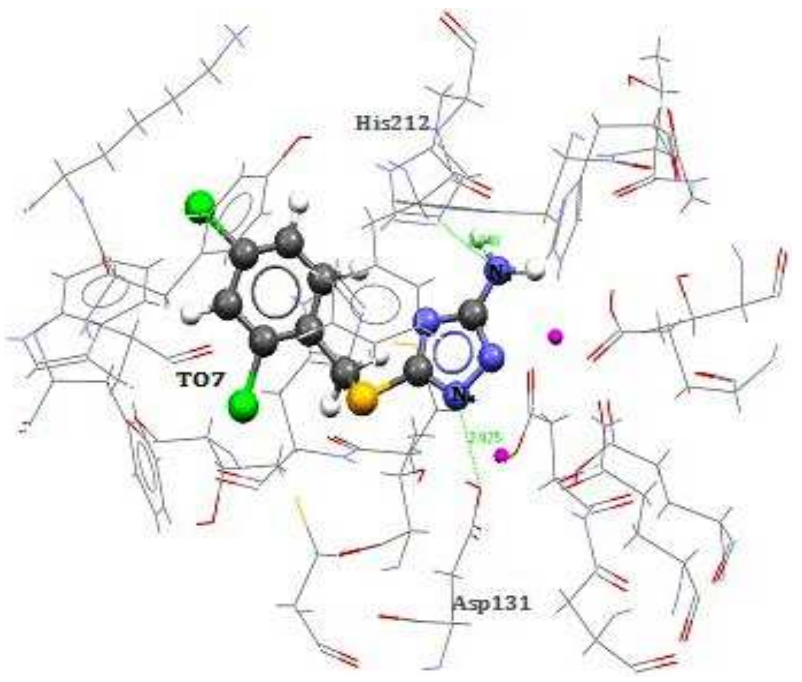

Figure 3. Representation of hydrogen bonds formed by the compound TO7

Hydrogen bonds are not solely responsible for the interaction of the ligand with MetAP. The role of Van der Waals bonds is also important in explaining, as reflected in the table 9 and figure 4 .

Table 9. The Van der Waals interactions

\begin{tabular}{lllll}
\hline $\mathbf{N}$ & Residues involved & Atom amino acid & Ligand Atom & Distance $\AA$ \\
\hline 1 & Lys98 & $\mathrm{H}_{\mathrm{D} 2}$ & $\mathrm{CL}_{2}$ & 2.299 \\
1 & $\mathrm{Mn} 286$ & - & $\mathrm{N}_{2}$ & 2.679 \\
1 & $\mathrm{Mn} 286$ & - & $\mathrm{N}_{4}$ & 2.113 \\
1 & $\mathrm{Mn} 287$ & - & $\mathrm{N}_{2}$ & 2.189 \\
1 & $\mathrm{Mn} 287$ & - & $\mathrm{C}_{8}$ & 2.873 \\
1 & $\mathrm{Mn} 287$ & - & $\mathrm{N}_{3}$ & 2.970 \\
1 & $\mathrm{Mn} 287$ & - & $\mathrm{H}$ & 2.420 \\
\hline
\end{tabular}




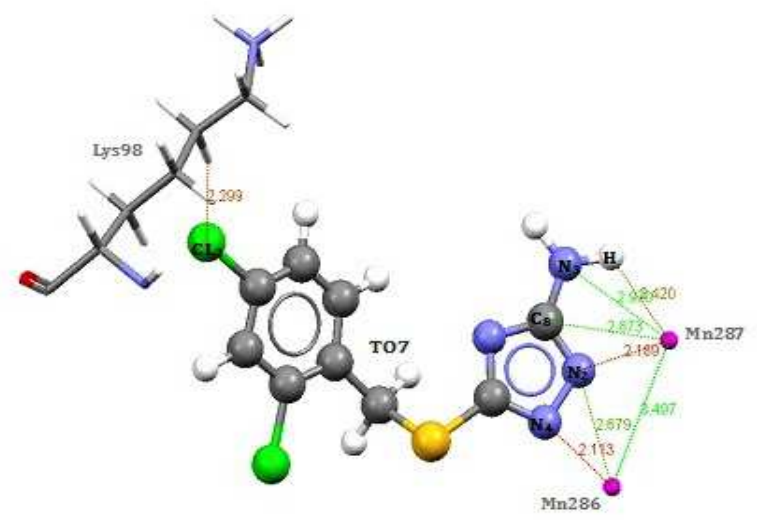

Figure 4. Representation of van der Waals interactions formed by the compound TO7

- Interaction: 3IU7-inhibitor 2

About the complex MetAp-inhibitor 2, the ligand formed a hydrogen bond and several Van der Waals interactions. The only hydrogen bond is formed with a distance of $2.863 \AA$ between $\mathrm{C}=\mathrm{O}$ of the ligand and one of the ring nitrogen atoms of the residue His205 (Figure 5).

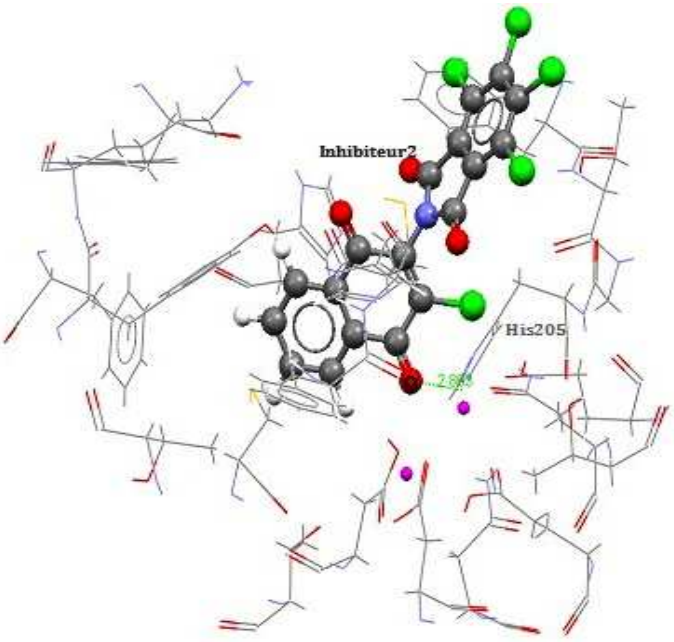

Figure 5. Representation of the hydrogen bond formed by inhibitor 2

In the following table we summarize the pairs of atoms interacting in different van der Waals interactions:

Table 10. The Van der Waals interactions

\begin{tabular}{|c|c|c|c|c|}
\hline $\mathbf{N}$ & Residues involved & Atom amino acid & Ligand Atom & Distance $\AA$ \\
\hline 1 & Glu238 & $\mathrm{C}_{\mathrm{D}}$ & $\mathrm{CL}$ & 2.924 \\
\hline 1 & His212 & $\mathrm{C}_{\mathrm{D} 2}$ & $\mathrm{O}$ & 2.526 \\
\hline 1 & His212 & $\mathrm{H}_{\mathrm{D} 2}$ & $\mathrm{O}$ & 1.914 \\
\hline 1 & Thr203 & $\mathrm{O}_{\mathrm{G} 1}$ & $\mathrm{C}$ & 2.654 \\
\hline 1 & Phe202 & $\mathrm{H}_{\mathrm{D} 2}$ & $\mathrm{O}$ & 2.123 \\
\hline 1 & Mn286 & - & $\mathrm{O}$ & 2.879 \\
\hline 1 & $\mathrm{Mn} 287$ & - & $\mathrm{O}$ & 2.229 \\
\hline 1 & Mn287 & - & $\mathrm{C}$ & 3.192 \\
\hline 1 & $\mathrm{Mn} 287$ & - & $\mathrm{CL}$ & 3.092 \\
\hline
\end{tabular}

Figure 6 shows the interactions:

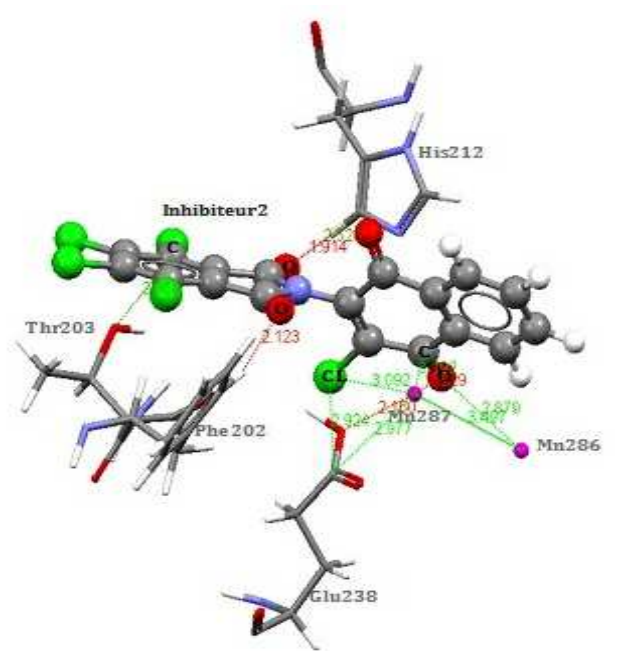

Figure 6.Representation of Van der Waals interactions formed by inhibitor 2

- Interaction: 3IU7- inhibitor21

The figure 7 shows the inhibitor 21 penetrates well into the active site of the enzyme, forming a single hydrogen bond with the residue His205 $\left(\mathrm{C}_{7}=\mathrm{O}_{2} \ldots \ldots . \mathrm{H}_{\mathrm{E} 2}-\mathrm{N}_{\mathrm{E} 2}-\mathrm{His} 205 ; \mathrm{d}=\right.$
$2.335 \AA$ ).

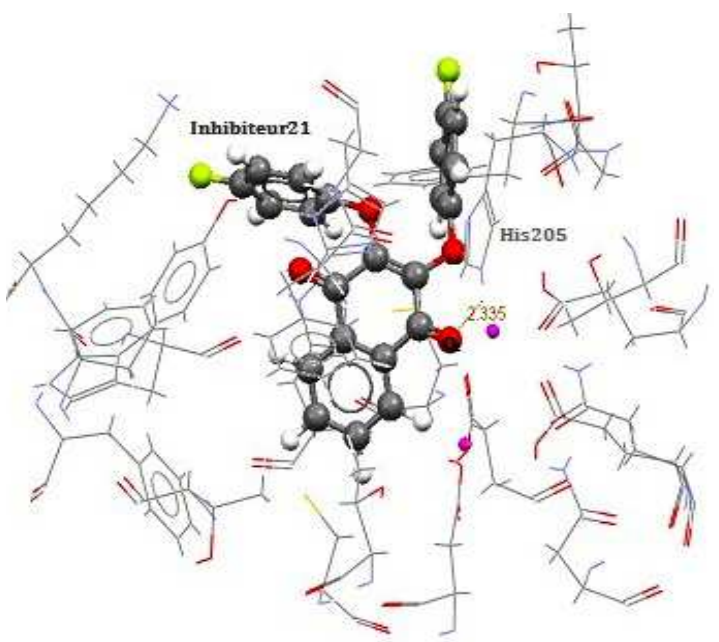

Figure 7. Representation of hydrogen bond formed by the inhibitor 21

The interactions of Van der Waals shown in table 11 and figure 8 below: 
Table 11. The Van der Waals interactions

\begin{tabular}{lllll}
\hline $\mathbf{N}$ & Residues involved & Atom amino acid & Ligand Atom & Distance $\AA$ \\
\hline 1 & Lys98 & $\mathrm{H}_{\mathrm{Z3}}$ & $\mathrm{F}_{2}$ & 2.115 \\
1 & $\mathrm{Asp} 131$ & $\mathrm{O}_{\mathrm{D} 2}$ & $\mathrm{H}_{1}$ & 2.209 \\
1 & $\mathrm{H} 203$ & $\mathrm{H}$ & $\mathrm{C}_{13}$ & 2.379 \\
1 & $\mathrm{H} 203$ & $\mathrm{C}_{16}$ & 2.327 \\
1 & $\mathrm{H}$ & $\mathrm{C}_{\mathrm{D} 2}$ & $\mathrm{H}_{5}$ & 2.396 \\
1 & $\mathrm{His} 205$ & - & $\mathrm{H}_{1}$ & 1.747 \\
1 & $\mathrm{Mn} 286$ & - & $\mathrm{C}_{1}$ & 2.808 \\
1 & $\mathrm{Mn} 286$ & - & $\mathrm{O}_{2}$ & 3.009 \\
1 & $\mathrm{Mn} 286$ & - & $\mathrm{O}_{2}$ & 1.710 \\
1 & $\mathrm{Mn} 287$ & - & $\mathrm{C}_{7}$ & 2.846 \\
\hline
\end{tabular}

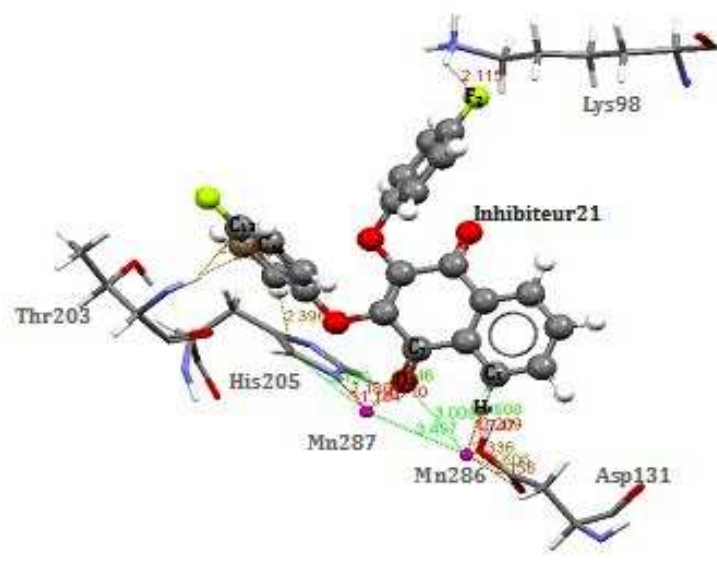

Figure 8. Representation of Van der Waals interactions formed by inhibitor21

- Interaction: 3IU7- inhibitor22

The inhibitor 22 establishes a single hydrogen bond with the amino acid Cys105 (Figure 9). This ligand is committed by one of these oxygen atoms bind to the $\mathrm{SH}$ group of Cys105 residue $\left(\mathrm{O} \ldots . . \mathrm{H}_{\mathrm{G}}-\mathrm{S}_{\mathrm{G}}-\mathrm{Cys} 105 ; \mathrm{d}=3.108 \AA\right)$.

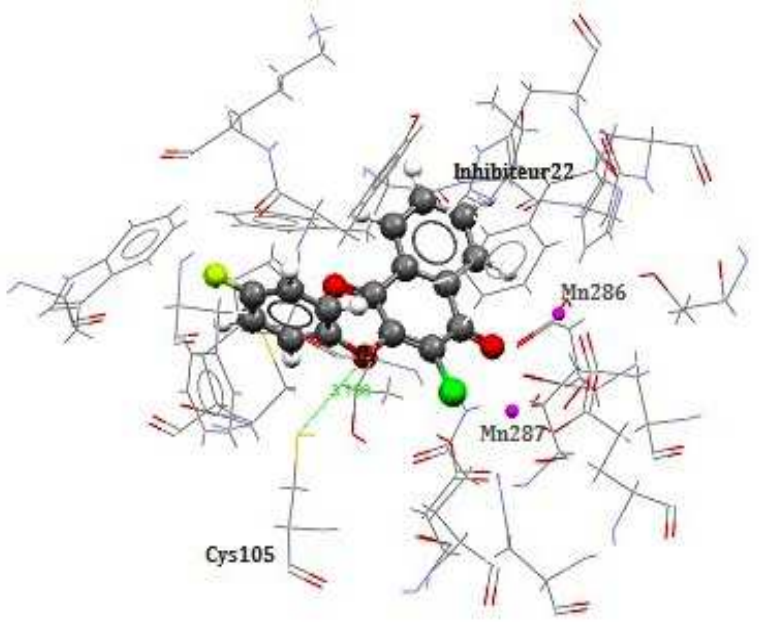

Figure 9. Representation of hydrogen bond formed by the compound 22

The Van der Waals interactions are summarized in table 12 and figure 10 below:

Table 12. The Van der Waals interactions

\begin{tabular}{|c|c|c|c|c|}
\hline $\mathbf{N}$ & Residues involved & Atom amino acid & Ligand Atom & Distance $\AA$ \\
\hline 1 & Tyr97 & $\mathrm{H}_{\mathrm{D} 2}$ & $\mathrm{H}_{8}$ & 1.877 \\
\hline 1 & Phe100 & $\mathrm{H}_{\mathrm{B} 2}$ & $\mathrm{~F}_{1}$ & 1.923 \\
\hline 1 & Phe100 & $\mathrm{H}_{\mathrm{D} 1}$ & $F_{1}$ & 1.933 \\
\hline 1 & Phe100 & $\mathrm{C}_{\mathrm{D} 1}$ & $\mathrm{~F}_{1}$ & 2.552 \\
\hline 1 & Phe100 & $\mathrm{C}_{\mathrm{D} 1}$ & $\mathrm{C}_{13}$ & 2.789 \\
\hline 1 & Cys 105 & $\mathrm{~S}_{\mathrm{G}}$ & $\mathrm{C}_{11}$ & 2.943 \\
\hline 1 & Cys 105 & $\mathrm{~S}_{\mathrm{G}}$ & $\mathrm{H}_{5}$ & 2.496 \\
\hline 1 & His114 & $\mathrm{N}_{\mathrm{E} 2}$ & $\mathrm{O}_{2}$ & 2.465 \\
\hline 1 & His 212 & $\mathrm{~N}_{\mathrm{E} 2}$ & $\mathrm{C}_{5}$ & 2.709 \\
\hline 1 & His 212 & $\mathrm{~N}_{\mathrm{E} 2}$ & $\mathrm{C}_{6}$ & 2.735 \\
\hline 1 & $\operatorname{Trp} 255$ & $\mathrm{C}_{\mathrm{H} 2}$ & $\mathrm{~F}_{1}$ & 2.354 \\
\hline 1 & $\operatorname{Trp} 255$ & $\mathrm{C}_{\mathrm{Z} 3}$ & $\mathrm{~F}_{1}$ & 2.172 \\
\hline 1 & Mn286 & - & $\mathrm{O}_{1}$ & 2.089 \\
\hline 1 & $\mathrm{Mn} 286$ & - & $\mathrm{C}_{10}$ & 2.989 \\
\hline 1 & Mn286 & - & $\mathrm{CL}_{1}$ & 2.660 \\
\hline 1 & $\operatorname{Mn} 287$ & - & $\mathrm{H}_{4}$ & 2.063 \\
\hline 1 & $\operatorname{Mn} 287$ & - & $\mathrm{C}_{6}$ & 3.080 \\
\hline 1 & $\operatorname{Mn} 287$ & - & $\mathrm{O}_{1}$ & 2.408 \\
\hline
\end{tabular}




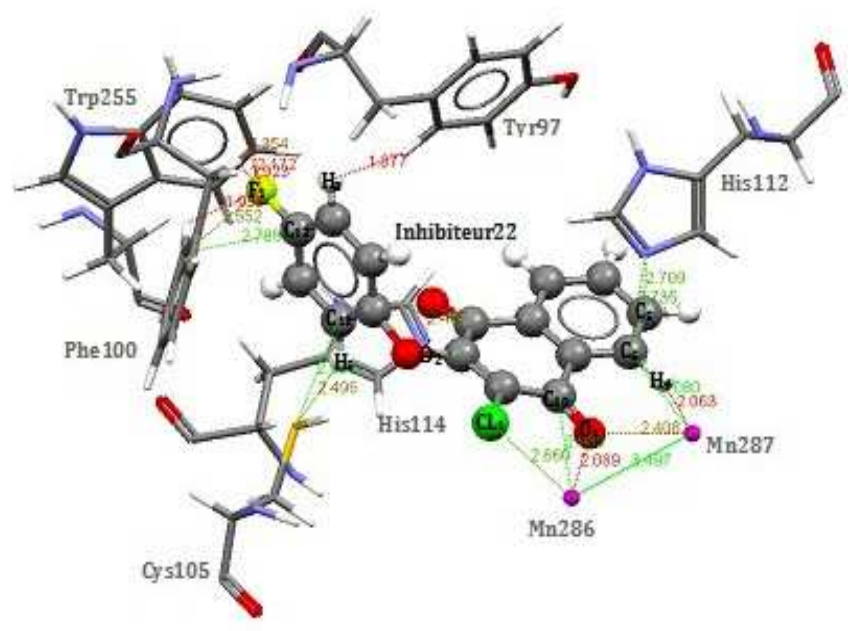

Figure 10. Representation of Van der Waals interactions formed by inhibitor 22

Among the four compounds studied, the compound TO7 forms the most stable complex protein-ligand; so it has the best inhibitory effect. In addition, this compound has all the requirements to be an excellent candidate as a drug, particularly a low molecular weight and $\log \mathrm{P}$ equal to 2.992 .

\section{Conclusion}

The main purpose of this study was to test the performance of certain molecular docking programs that simulate the interactions between proteins and ligands. To study these interactions, we chose two molecular docking programs: Surflex, which uses incremental method and GOLD, which uses a genetic algorithm. These programs were developed to assist in the development of molecules with therapeutic activity.

In this context, we have used these programs to study the interactions involved in the inhibition of methionine aminopeptidase by various inhibitors. The latter is a potential therapeutic target in Mycobacterium tuberculosis infection. In the first part of our work we tested the two programs Surflex and GOLD according to two criteria: the RMSD between the predicted mode of interaction and the crystal structure and the correlation between the biological activity $\left(\mathrm{IC}_{50}\right)$ of the molecules studied (from the literature) and the score of molecular docking (Affinity-Surflex and FitnessGOLD). Both programs, Surflex and GOLD can be considered as sufficiently effective reproduce quite well the experimental results with over $66 \%$ of the values of RMSD below $2 \AA$ for the former and $79.16 \%$ for the second. In addition, a positive correlation between the two parameters analyzed with $r=0.76$ and $r=0.64$ respectively.

In the second part of this work we have tried to contribute firstly, understanding the basic mechanisms of the bond between a target protein and its ligand and the other to search of potential therapeutic agents by molecular docking.

For this, we studied the inhibition of MetAP by various molecules from the literature and also visualized the links they involve the active site of this enzyme. The results are generally similar for both programs Surflex and GOLD. The study showed that the compound TO7 (Affinity $=3.10 \mathrm{M}^{-1}$, Fitness $=57.35)$ has the best inhibitory effect of MetAP.

Finally, it is important to note that different inhibitors of methionine aminopeptidase tested in this study are generally consistent with the criteria required by the rule of Lipinski.

\section{References}

[1] Chikhi A and Bensegueni A. Comparative Study of the Efficiency of Three Protein-Ligand Docking Programs. Journal of Proteomics \& Bioinformatics, 1, 161-165. 2008

[2] Olaleye A. O., Bishaie W. R., Liua J. O. Targeting the role of $\mathrm{N}$-terminal methionine processing enzymes in Mycobacterium Tuberculosis. Tuberculosis89, S1, S55- S59. 2009

[3] Olaleye O., Raghunand T. R., Bhat S., He J., Tyagi S., Lamichhane G., Gu P., Zhou J., Zhang Y., Grosset J., Bishai W. R., Liu J. O.Methionine Aminopeptidases from Mycobacterium tuberculosis as Novel Antimycobacterial Targets. Chemistry \& Biology, 17, 86-97. 2010

[4] Kramer B., Rarey M., Lengauer T. Evaluation of the FLEXX Incremental Construction Algorithm for Protein-Ligand Docking. Proteins: Structure, Function, and Genetics, 37, 228-241.1999

[5] Kellenberger E., Rodrigo J., Muller P., Rognan D. Comparative Evaluation of Eight Docking Tools for Docking and Virtual Screening Accuracy. Proteins: Structure, Function, and Bioinformatics, 57, 225-242. 2004

[6] Fox W. Statistiques Sociales. $3^{\text {éme }}$ édition. France: De Boeck. 1999. $374 \mathrm{p}$.

[7] Evdokimov A. G., Pokross M., Walter R. L., Mekel M., Barnett B. L., Amburgey J., Seibel W. L., Soper S. J., Djung J. F., Fairweather N., Diven C., Rastogi V., Grinius L., Klanke C., Siehnel R., Twinem T., Andrews R., Curnow A. Serendipitous Discovery of Novel Bacterial Methionine Aminopeptidase Inhibitors. Proteins: Structure, Function, and Bioinformatics, 66, 538-546. 2007

[8] Altmeyer M. A., Marschner A., Schiffmann R., Klein C. D. 2010. Subtype-selectivity of metal-dependent methionine aminopeptidase inhibitors. Bioorganic \& Medicinal Chemistry Letters, 20, 4038-4044. 2010

[9] Huang Q. Q., Huang M., Nana F. J., Ye Q. Z. Metalloformselective inhibition: Synthesis and structure-activity analysis of $\mathrm{Mn}(\mathrm{II})$-form-selective inhibitors of Escherichia coli methionine aminopeptidase. Bioorganic \& Medicinal Chemistry Letters, 15, 5386-5391. 2005

[10] Berman H. M. The Protein Data Bank: a historical perspective. ActaCryst, A64, 88-95. 2008

[11] Protein Data Bank (PDB). Biological Macromolecular Resource. [En ligne]. http://www.pdb.org/pdb/home.

[12] Mark A. ArgusLab (version 4.0.1). Thompson. Planaria software LLC. Seattle. http://www.ArgusLab.com.

[13] BioPharmics LLC. 2005.Surflex Manual: Docking and Similarity (version 1.3). 
[14] Lipinski C. A., Lombardo F., Dominy B. W., Feeney P. J. Experimental and computational approaches to estimate solubility and permeability in drug discovery and development settings.Advanced Drug Delivery Reviews, 46, 326. 2001

[15] Gabb H. A, Jackson R. M, Sternberg M. J. Modelling protein docking using shape complementarity,electrostatics and biochemical information. J Mol Biol, 272, 106-120.1997

[16] Zaheer-ul-Haq, Halim S. A, Uddin R, Madura J. D. Benchmarking docking and scoring protocol for the identification of potential acetyl cholinesterase inhibitors. $J$ Mol Graph Model, 28, 870-882.2010

[17] Lape M, Elam C, Paula S. Comparison of current docking tools for the simulation of inhibitor binding by the transmembrane domain of the sarco/ endoplasmic reticulum calcium ATPase. Biophys Chem, 150, 88-97.2010

[18] Bensegueni A. Etude théorique des métabolites secondaires des végétaux et des composés de synthèse sur le plan de l'activité biologique : simulation par docking (arrimage) moléculaire sur la lipoxygénase et la cyclooxygénase. Thèse de doctorat en Biochimie Appliquée. Constantine : Université Mentouri Constantine. Algérie. 2007. 76p.

[19] Chikhi A., Bensegueni A. In Silico Study of the Selective Inhibition of Bacterial Peptide Deformylases by Several Drugs. Journal of Proteomics and Bioinformatics, 3, 061-065. 2010

[20] Kamel M. M., Ali H. I., Anwar M. M., Mohameda N. A., Soliman A. M. Synthesis, antitumor activity and molecular docking study of novel Sulfonamide-Schiff's bases, thiazolidinones, benzothiazinones and their C-nucleoside derivatives. European Journal of Medicinal Chemistry, 45, 572-580. 2010

[21] Maouche A. T., Maouche B., Kellou S. T., El-Aoufi S., Martínez M. M., Muñiz R. G., Fourmy D., Maigret G. Exploring the binding pocket for pyridopyrimidine ligands at the CCK1 receptor by molecular docking. Journal of MolecularModeling, 14, 303-314. 2008

[22] Molinspiration. [En ligne]. http://www.molinspiration.com/. 